\title{
Lamartine et les catholiques de France et du Canada (1ère partie)
}

\section{Robert Sylvain}

Volume 4, numéro 1, juin 1950

URI : https://id.erudit.org/iderudit/801615ar

DOI : https://doi.org/10.7202/801615ar

Aller au sommaire du numéro

Éditeur(s)

Institut d'histoire de l'Amérique française

ISSN

0035-2357 (imprimé)

1492-1383 (numérique)

Découvrir la revue

Citer cet article

Sylvain, R. (1950). Lamartine et les catholiques de France et du Canada (1ère partie). Revue d'histoire de l'Amérique française, 4(1), 29-60.

https://doi.org/10.7202/801615ar d'utilisation que vous pouvez consulter en ligne.

https://apropos.erudit.org/fr/usagers/politique-dutilisation/ 


\title{
LAMARTINE ET LES CATHOLIQUES DE FRANCE ET DU CANADA ${ }^{1}$
}

\author{
1ère partie
}

Lamartine connut chez nous, au dix-neuvième siècle, une singulière faveur. Les prestiges et les enchantements de son art tirèrent nos premiers lettrés de la torpeur où ils avaient sombré en compagnie de Boileau et de Laharpe. Ayant changé de guides, les poètes canadiens changèrent de Parnasse. L'influence de la muse lamartinienne, amorcée vers 1830, gagna peu à peu en amplitude et en profondeur; dans la deuxième partie du siècle, elle était devenue prépondérante. Les œuvres de l'auteur des Méditations constituaient alors "l'inspiration maîtresse" ${ }^{2}$ de maints de nos rimeurs.

Nonobstant ce fait littéraire bien établi, peut-on écrire, avec M. Van Tieghem, que Lamartine "fut gouté pleinement" ${ }^{3}$ au Canada ? Le déisme, qui trop souvent affleure, quand il ne projette pas hardiment l'audace de ses arguments fallacieux, dans les nombreuses pages que le grand écrivain livra au public à partir de 1835, n'entama-t-il en rien la fervente admiration que le chantre de La Priere avait fait sourdre dans le cœur des Canadiens français? Il eût été certes étrange que le poète du Crucifix, après avoir été l'idole des catholiques, en France, puis renié par eux après la publication du Voyage en Orient, de Jocelyn et surtout de la Chute d'un Ange, fat encore l'objet, dans nos chapelles littéraires, d'un culte sans dissidence. Des faits d'abord

1. M. Séraphin Marion, dans une étude trop circonscrite, a traité un aspect de ce problème d'histoire: "Lamartine et l'Institut Canadien de Montréal", dans la Revue de l'Université d'Ottawa, 20 (janvier-mars 1950:): 23-47.

2. E. Préclin, dans la Revue historique, 178 (juillet-aoat 1936), 113. (Compte rendu critique de l'ouvrage de Laurence A. Bisson, Le Romant isme littéraire au Canada français).

3. Paul Van Tieghem, Le Romantisme dans la littérature européenne (Coll. Evo. lution de l'humanité, Paris, 1948), 193. 
sporadiques révélèrent que l'orientation définitive de la pensée de Lamartine n'avait pas échappé à la clairvoyance de quelques-uns de nos intellectuels; mais if fallut le zèle publicitaire déployé, à Montréal et à Québec, par l'un de ses fidèles en faveur de la dernière production de sa plume infatigable, pour mettre en évidence qu'ici, comme outreAtlantique, on avait pris mesure exacte de son christianisme et qu'on n'entendait pas être dupe de la marchandise offerte. Et comme Louis Veuillot, le chef reconnu, à l'époque, des ultramontains des deux mondes, aimait à dire "le mot catholique sur l'événement de chaque jour", il intervint dans la querelle et engagea une longue polémique qui, finalement, de répercussions en répercussions, ne fut pas sans contribuer à la suppression de son journal, en 1860 .

Des "lamartiniens" ont sévèrement reproché à Veuillot son rôle dans ces conjonctures. On a parlé de "coup de poignard" 4, de "violente diatribe", de "concert d'injures" 5, de "bolées de vitriol" lancées "périodiquement, dans l'Univers", "à la face" de Lamartine ${ }^{6}$. Une enquête menée aussi consciencieusement que possible sur les rapports de l'illustre poète avec les catholiques de France et du Canada, pourra peut-être faire justice de ces outrances verbales et expliquer, sinon justifier complètement, l'attitude du rédacteur en chef de l'Univers. Toutefois, pour mettre au clair cette page de l'histoire des idées en notre pays, qu'on nous pardonne de reprendre les faits d'assez loin.

Le jeune poète des Méditations s'était révélé à son heure. La religion avait perdu ses chantres profanes comme ses chantres sacrés. Plus de poésie en France, que la poésie d'épopée, de tragédie, toute de convention, de l'Empire. Chateaubriand avait retrouvé la prose; la poésie venait d'être captée de nouveau par Lamartine; ou plutôt c'était la même poésie sous deux aspects différents, la poésie dans la

4. Henri Guillemin, Connaissance de Lamartine (Fribourg, 1942), 284.

5. Camille Latreille, Lamartine, poète politique (Annales del'Université de Lyon, Facicule 36, Lyon, 1924), 108, 114.

6. Henri Guillemin, Lamartine: l'homme et l'œuvre (Paris, [ 1940 ]), 135. 
prose, la poésie dans les vers. Aussi, même enthousiasme en 1820, a l'apparition des Méditations, qu'en 1802, à la naissance du Génie du Christianisme, avec plus de concert, plus d'unanimité dans la louange.

Nulle part ailleurs que dans les rangs des catholiques l'éloge n'avait été plus sincère et plus chaleureux. C'est là que la voix du poète avait trouvé le meilleur écho. Il parlait, dans une langue mélodieuse, de Dieu, de la prière, de la croix, du ciel. Comment son accent n'aurait-il pas plu infiniment à l'oreille catholique? Voilà pourquoi l'aède chrétien, le chantre inspiré par des thèmes religieux, fut béni, célébré, adopté d'emblée, comme on avait fait d'un Chateaubriand quelques années plus tôt.

N'avait-on pas cédé à un enthousiasme irréfléchi? Pourquoi ne s'était-on pas demandé un seul instant si on n'errait pas lourdement en appuyant sur la note catholique de la poésie lamartinienne?

L'écrivain prestigieux était, sans conteste possible, sincère. Il s'était converti au début de 1820 . Jusqu'à cette époque, il avait mené l'existence d'un sceptique d'abord indifférent, mais dont la quiétude avait fini par faire place au trouble et à l'anxiété. "La foi très vive, très scrupuleuse, de ses années de collège, s'était évanouie dans le grand tumulte charnel de son adolescence." 7 Voulant reconquérir la paix de la conscience et se remettre dans l'ordre, avant son mariage, il avait fait une confession générale. La lutte morale s'était terminée par une victoire, mais on ne peut pas en dire autant de l'adhésion au dogme. "... il exécute sur lui-même ce que $M$. Guillemin appelle un "coup de force". Il veut croire, donc il croit... Il s'interdit le doute, qui n'était pas pour lui un mol oreiller, et par un effort de volonté devient croyant." 8

Les Méditations devaient naturellement refléter cet état d'âme. Aussi un œil exercé aurait-il pu déceler, sous la piété de l'effusion, le déisme latent. Le mal dont Lamartine donnerait plus tard de si nombreux exemples, existait dans sa première œuvre. Un érudit qui a rigoureusement vérifié, à l'aide de recherches infinies, les différentes influences qui se sont exercées sur le jeune poète, n'hésite pas à prononcer l'arrêt suivant: "Le catholicisme, chez lui, a enveloppé, non

7. Henri Guillemin, Le Jocelyn de Lamartine (Paris, [s.d. ]), 165.

8. Marquis de Luppé, Les Travaux et les Jours d'Alphonse de Lamartine (Paris, ( 1948 i), 203. 
pas chassé le déisme." 9 Toutefois les catholiques, en 1820 , ne purent en aucune façon soupçonner l'évolution ultérieure de Lamartine: ils n'avaient pas discerné, grâce à quelques indices, extrêmement ténus, il est vrai, les tendances fondamentales de sa pensée.

Ils commirent la même erreur d'appréciation lors de la publication des Harmonies poétiques et religieuses, dix ans plus tard. Lamartine était célébré par le Correspondant (22 juin 1830) "comme le plus grand poète catholique de l'heure." $10 \mathrm{Il}$ avait composé ces poèmes pour plaire a sa mère, "pour lui donner cette joie de voir son fils employer enfin son talent, comme elle le lui avait si souvent demandé, à chanter la gloire du Créateur."'11 Nombreuses étaient les inspirations chrétiennes et sublimes qui pouvaient combler l'attente maternelle; mais des observateurs perspicaces purent discerner, dans le même recueil, quelques symptốmes d'un christianisme qui se séparait de plus en plus des sources positives, certaines traces d'une religiosité équivoque qui tournait au panthéisme et au naturalisme. Eugène Sue, Sainte-Beuve et Pierre Leroux furent au nombre de ces critiques clairvoyants. Mais on pouvait les croire intéressés à laisser planer des doutes sur l'orthodoxie de Lamartine. Seul parmi les catholiques, Xavier de Maistre perçut clairement que la foi du poète commençait à se démanteler ${ }^{12}$.

Il n'avait que trop raison. C'est à cette époque, en effet, que l'écrivain penche de plus en plus vers le rationalisme. Non pas qu'il ait abandonné les pratiques religieuses, du moins celles qui sont essentielles, mais son esprit adhère de moins en moins au dogme catholique. Un homme, qui vient de s'introduire dans son intimité, n'est pas étranger à ce lent travail de désagrégation. Il s'appelle Jean-Marie Dargaud. "Libre penseur farouche, infatigable dialecticien, apôtre souvent indiscret", 13 il va tout tenter pour convertir son illustre ami à ses idées.

9. Gustave Lanson, Lamartine. Méditations poétiques. Nouvelle édition publiée d'après les manuscrits et les éditions originales avec des variantes, une introduction et des notes. (Coll. des Grands Ecrivains de la France, Paris, 1915), 25. - Paul Hazard avait également conclu que le poète des Méditations avait surtout assimilé, avoc la Bible, Voltaire et Rousseau: c'était la "ses plus substantielles nourritures". Cf. Marius-François Guyard, "Les Influences étrangères dans la Chute d'un Ange", Revue de Litterature comparé, 21 (avril-juin 1947), 263.

10. Cité par Guillemin, Le Jocelyn de Lamartine, 186.

11. Guillemin, ibid., 60.

12. Guillemin, ibid., 186.

13. Jean-Marie Carré, "Lamartine et Michelet d'après leur correspondance inédite", Revue des Deux Mondes, ler septembre 1926, 184. 
Il n'y réussira que trop. Son action ne fera que renforcer celle d'Aimé Martin qui, à partir de 1822 environ et surtout depuis son séjour à Florence, pendant lequel il avait été reçu à la Légation de France par Lamartine, entretenait des rapports amicaux avec le poète. Voltairien, il avait hérité du déisme de Bernardin de Saint-Pierre, dont il avait épousé la veuve. Par la publication, en 1831, de son Abrégé de l'histoire du Christianisme, et, en 1836, de l'Education des mères de famille ou la civilisation du genre humain par les femmes, il révéla une hostilité irréductible à l'égard de l'Église. ${ }^{14}$ Lamartine ne trouva que trop dans sa conversation comme dans celle de Dargaud les arguments qui l'aideront à se détacher de la foi de son enfance.

Ce lent travail d'imprégnation aurait peut-être mis des années avant d'aboutir au résultat ardemment escompté. Mais un événement cardinal précipita la cristallisation de l'incroyance dans un esprit déja saturé par les innombrables sophismes de l'irréligion.

En juillet 1832, Lamartine partait, à la "joie" des catholiques, pour l'Orient, "pour la terre des miracles et des prodiges"; l'objet ultime de son pèlerinage était de "visiter le tombeau de Jésus"15. Le 20 octobre, il s'agenouillait au Saint-Sépulcre. A lire la relation de son voyage, on pourrait croire que c'est de sa méditation au tombeau du Christ que date la "grande lumière" qui, dans son âme, éclaira "Dieu, l'Etre suprême, et non pas le Christ". ${ }^{16}$ Majs M. Guillemin pense que le drame spirituel de Lamartine ne se joua pas à Jérusalem, mais au retour, à Beyrouth, lors de la mort de sa fille Julia. "Ce fut pour son père une douleur sans nom; l'abîme s'ouvrait sous ses pieds. Dans ce gouffre, avec son bonheur, s'engloutit d'un seul coup l'édifice tremblant et déjà plus qu'à demi ruiné de sa foi." ${ }^{7}$

La crise religieuse s'est dénouée brusquement. Une catastrophe domestique a joué le rổle de catalyseur. Les velléités rationalistes se

14. Luppé, op. cit., 199.

15. Annales de philosophie chretienne, 10 (30 juin 1835): 403.

16. Luppé, op. cit., 171. - De même dans une lettre à Montalembert, $1^{\text {er }}$ septembre 1834, au sujet d'un projet de voyage en Orient, Lamartine écrit: "Vous allez visiter des scènes historiques, politiques, religieuses qui jetteront une grande lumière sur les différents drames que l'humanité a joués et jouera avant, pendant et après nous. Vous en reviendrez comme moi éclairé et changé". C'est nous qui soulignons. (Cité par P. de Lallemand, Montalembert et ses amis dans le Romantisme (18301840) (Paris, 1927), 84).

17. Guillemin, Le Jocelyn de Lamartine, 206. 
sont désormais durcies en résolutions irréformables. "De 1833 jusqu'à sa mort, Lamartine demeurera le même, irréductible, irréconciliable a l'egard du catholicisme."18

Ayant renié ses premières croyances, l'écrivain se forma cette religion pour "lui seul" que M. Jean des Cognets résume parfaitement dans les quelques points suivants: "Croyance très vive, très profonde, très tendre en un Dieu personnel qui n'est pas le Christ...; charité prodigue envers le prochain; pardon sincère des injures reçues... sentiment très net du devoir civique, dévouement de chacun selon ses forces au bien général; inflexible attachement aux vertus de la famille, base nécessaire de toute société." 19

Ce nouveau credo, Lamartine ne le révèle pas immédiatement qu public. Il n'est pas pressé de s'attirer les récriminations des catholiques. D'ailleurs une telle manifestation, en 1833, serait bien intempestive, puisqu'elle nuirait aux débuts de sa vie politique. Élu député de Bergues durant son voyage en Orient, il parle et agit, à la Chambre, comme un catholique, jusqu'à parfois, écrit le Marquis de Luppé, "nous paraître de quelque duplicité." 20 Il prend la défense des insurgés vendéens; il s'indigne contre les pétitionnaires du petit bourg breton de Vitré, qui voulaient obtenir le renvoi des Frères des Écoles chrétiennes, “des hommes, s'écrie Lamartine, qui ne font d'autre vœu que de consacrer leur vie à la propagation de la morale évangélique, des hommes qui ne demandent que la liberté du dévouement, que le droit de se sacrifier gratis, ou pour un prix qui n'est pas de ce monde, à l'enseignement des classes pauvres!" ${ }^{21}$ Il souhaite l'ouverture au culte de Saint-Germain l'Auxerrois; il regrette le petit nombre de prêtres dans les diocèses de France; le 8 mai 1834, il ne craint pas d'affirmer que "le christianisme, cet immortel enseignement des âmes... se résuma dans l'Église pour s'emparer du monde qu'il avait mission de régénérer" ${ }^{2}$.

18. Guillemin, Lamartine: l'homme et l'œuvre, 111.

19. Jean des Cognets, La Vie intérieure de Lamartine selon les souvenirs inédits de son plus intime ami, J.-M. Dargaud, et les travaux les plus récents. (Paris, 1913), 347.

20. Luppé, op. cit., 277.

21. Cité par Georges Rigault, Histoire générale de l'Institut des Frères des Écoles chretiennes (Paris, 1945), V: 114.

22. Cité par Guillemin, Le Jocelyn de Lamartine, 241. 
Mais en même temps qu'il s'attirait, en parlant de la sorte, les applaudissements des catholiques, Lamartine rédigeait le Voyage en Orient, qui parut, en quatre volumes, dans le mois d'avril 1835. C'était la première fois qu'il faisait connaitre au grand public la transformation radicale qui s'était produite dans sa pensée religieuse.

Ce n'est pas sans déchirement et sans douleur que les publicistes catholiques s'occupèrent du funeste ouvrage. Celui qu'ils avaient appelé jusqu'alors "notre Lamartine" se révélait un voltairien, pis, à l'immense affliction d'un Ozanam ${ }^{23}$, l'apologiste du Coran et de l'islamisme. "Nous le disons sans détour", écrivait le rédacteur des Annales de philosophie chrétienne, "à peine y avons-nous reconnu quelques traces d'un Christianisme vague et tout philosophique. Il y a là du déisme, du philosophisme, du rationalisme, du Saint-Simonisme, du panthéisme, mais nulle part il n'est fait mention de l'Église catholique. $\mathrm{Au}$ contraire, cette mère des chrétiens y est souvent blâmée, calomniée, même, dans sa discipline et dans ses dogmes, mise au-dessous du mahométisme!' ${ }^{4}$ Et le critique soulignait que les procédés de l'écrivain n'avaient rien de bien neuf; c'était avec les armes du déisme du dixhuitième siècle que Lamartine se révoltait contre l'Église et qu'il prétendait instaurer ce qu'il appelait la "religion de l'avenir".

Mais on voulait croire que "les sentiments personnels de l'auteur" étaient "différents" de ceux qui étaient "exprimés dans son ouvrage". ${ }^{2}$ On se refusait à faire de l'illustre poète, une recrue définitivement perdue pour l'Église, comme La Mennais.

Ce furent de semblables doléances mais sensiblement plus chagrines, qui se firent entendre, l'année suivante, à la parution de Jocelyn. Cette publication "élargit le fossé qui depuis le Voyage en Orient séparait Lamartine de l'Église. A lire leurs journaux, on comprend quel déchirement les catholiques éprouvent de perdre une de leurs gloires les plus caressées." 26 "Nous le disons avec vérité", écrivait Augustin Bonnetty, "c'est avec douleur que nous voyons M. de Lamartine s'égarer dans une voie qui s'ouvre pourtant toute unie et

23. J.-M. Carré, loc. cit., 188.

24. Annales de philosophie chrétienne, 10 (30 juin 1835): 404.

25. Ibid., 405.

26. J. des Cognets, op. cit., 269. 
toute facile devant lui" ${ }^{2}$. Son œuvre, au jugement du même censeur, était "sans unité, sans vérité, sans personnalite". "M. de Lamartine n'a pas donné, comme il le prétend cependant, un type chrétien, le type $d u$ prêtre catholique; non, ce n'est pas là le prêtre catholique." 28

$L ' A m i$ de la Religion n'était pas moins catégorique. Le mécontentement qu'éprouvait le rédacteur au sujet de la récente publication le rendait sévère pour l'affabulation de l" Épisode": "M. de Lamartine, écrivait-il, qui veut nous offrir un poème avec toute la vérité de l'histoire était tenu à une scrupuleuse exactitude. Cette exactitude, il ne l'a point respectée. Il a beau nous dire que son curé n'est poin't une invention, que c'est un récit: cela peut être; mais ce n'est point le type chrétien de notre époque, comme il le soutient; ce n'est point le prêtre évàngélique...; c'est un prêtre très romanesque, puisqu'il est le héros d'un roman, et d'un fort mauvais roman." 29

La sévérité du verdict des deux publicistes religieux n'excluait pas, cependant, tout espoir de voir enfin un aussi beau génie prêter une oreille docile aux appels de ceux qui ne voulaient pas qu'il s'égarât définitivement. "Écoutez, poète, ces voix amies", ${ }^{30}$ le pressaient les Annales de philosophie chrétienne. L'Ami de la Religion se refusait à croire que l'auteur de poèmes qui exaltaient avec une rare magnificence la gloire de Dieu se fât à jamais éloigné de la vérité catholique: "M. de Lamartine y reviendra tôt ou tard, à cette vérité; ce n'est pas la première fois que le doute entre dans son âme; mais il n'a jamais pu s'y fixer; et soyez-en sûrs, il n'y est pas encore bien établi." 31

Il fallut la publication, en 1838, de la Chute d'un Ange, pour dissiper d'aussi tenaces illusions. On répugnait à se rendre compte de la réalité. On voulait espérer contre toute espérance. N'est-elle pas touchante, cette confiance qui s'obstine à ne pas se laisser entamer, malgré l'évidence qui, de livre en livre, accusait toujours davantage l'incrédulité où Lamartine s'était laissé choir? Malgré qu'on en eât, on dut accepter le fait accompli, et c'est avec une colère que doublaient tant d'espoirs irrémédiablement avortés, que le rédacteur des Annales de

27. Annales..., 12 (31 mars 1836): 220.

28. Ibid., 197.

29. L'Ami de la Religion, 88 (19 mars 1836): 531.

30. Annales..., 12 (31 mars 1836): 220.

31. L'Ami de la Religion, 88 (19 mars 1836): 529. 
philosophie chrétienne stigmatisait les rêveries d'une religion nouvelle, les attaques contre les Écritures, contre les miracles, contre Jésus; le mélange grossier de déisme, de panthéisme et de matérialisme; les tableaux et les peintures obscènes; les démentis à l'histoire et à toutes les traditions de l'humanite. Cette implacable recension de la Chute d'un Ange, qui commençait par la question: "Qu'est donc cet homme, pour avoir fait un semblable livre?", se terminait par ce verdict depourvu de toute aménité: "C'est une œuvre d'un esprit malade et détourné de sa route, d'une âme creuse, qui n'a retenu aucune des paroles de Dieu; c'est en un mot une auvre mauvaise." 32

L'Univers religieux accentuait encore l'âpreté de cette condamnation: "Jusque-là, y écrivait-on, nous nous sentions saisis de pitié pour les infirmités de cette belle imagination, mais actuellement c'est d'horreur et de dégoût que nous sommes émus. L'impiété de ses paroles et leur outrageante impudeur provoquent un légitime mépris." 33

L'ouvrage qui, suivant l'appréciation d'un critique catholique, révélait une "double et triple chute: chute de l'ange, chute du chrétien, chute du poète," avait donc ouvert "les yeux à tous" 34 . Aussi ce n'est plus au poète chrétien, mais au transfuge et à l'apostat qu'on s'en prend, en 1839, après la publication des Recueillements poétiques. Lamartine n'y adressait-il pas aux prêtres, aux "nouveaux fils des saintes demeures", cette étrange exhortation:

Déchirez ces lambreaux des voiles du saint lieu;

Laissez entrer le jour dans cette nuit du temple:

Plus il fait clair, mieux on voit Dieu!35

32. Annales..., 16 (31 mai 1838): 364-388. - Un autre catholique, celui-là illustre, puisqu'il s'agit de Silvio Pellico, éprouva un vif chagrin a la lecture de cet ouvrage. "La Chute d'un Ange, écrivait-il à Théophile Foisset, le 6 juillet 1838, nous fait de la peine. Il y règne un mauvais goat moral qui choque. Au moins il parait qu'il fera peu de mal grâce à son manque d'intérêt. Prions pour l'auteur; je ne conçois pas ce qui lui est arrivé pour perdre ainsi le tact du beau, du bon, du vrai, après l'avoir possédé si glorieusement. Ah! c'est que la foi est une grâce! Dieu l'ôte à ceux qui sont idolâtres de leur propre intelligence. Le sublime des génies, c'est quand ils sont humbles." (Cité par Cargill Sprietsma, Revue des Cours et Conférences, 37e année, 30 avril'1936: 183).

33. Cité par J. des Cognets, op. cit., 287. 283.

34. U. Maynard, “M. de Lamartine”, Bibliographie catholique, 21 (avril 1859):

35. A M. de Genoude, sur son ordination. 
Car, à l'avenir, il n'y aura plus de cultes:

Minarets, pagodes et dômes

Sont écroulés sur leurs fantômes,

Et l'homme, de ces dieux vainqueur,

Sous tous ces temples en poussière

N'a ramassé que la prière,

Pour la transvaser dans son oœur! $!^{36}$

Dès maintenant, il n'y a qu'une seule foi qui

N'est que l'image immense et pure

Que le miroir de la nature

Fait rayonner dans la raison. ${ }^{37}$

De telles affirmations convainquaient les plus incrédules que Lamartine avait émigré dans le camp des rationalistes. Et comme la critique était unanime à souligner la décadence progressive de son art, on ne fut pas lent à rattacher, comme l'effet à sa cause, la chute du poète à la défection du croyant. Rendant compte des Pèlerinages de Suisse, ouvrage d'un jeune homme alors inconnu, Louis Veuillot, J.B.L. citait un fragment de la lettre écrite du lac Noir, à minuit, et déclarait que "cette lettre si chrétienne [ était] un chef-d'œuvre de sentiment et d'expression", et que dans Lamartine, on ne trouverait "rien qui approche, par l'expansion naturelle, profonde et touchante, de cette lettre": le poète n'avait plus "l'âme gonflée et l'intelligence enrichie de la sève divine de la foi religieuse, qui seule féconde le talent de l'écrivain, l'élève toujours et l'empêche de décliner" ${ }^{38}$.

Lamartine, Louis Veuillot: la rencontre de ces deux noms, en 1840, dans le même article d'un journal catholique méritait, ce semble, d'être signalee, car elle n'est pas fortuite. Elle marque, en effet, une étape importante dans les relations du poète avec le groupe dont Veuillot

36. Utopie.

37. Ibid.

38. Univers, 4 février 1840. 
deviendra le porte-parole quasi officiel. C'est précisément en cette même année 1840 que le journaliste, converti depuis deux ans, commence à collaborer assidûment à l'Univers, ${ }^{3} 9$ quotidien dont Montalembert rêvait de faire "l'organe central du catholicisme européen". 40 Peu à peu le jeune publiciste excite la curiosité, puis retient l'attention et finalement s'impose par la fermeté de sa pensée et par la qualité de sa langue, robuste et saine, pleine de trait et de nerf. Rédacteur en chef en 1843, il finira par réaliser l'idéal caressé par le zèle impétueux, mais moins réglé que celui du plébéien, du noble comte.

De tous les romantiques, il est probable ${ }^{41}$ que c'est Lamartine que Louis Veuillot a le plus admiré durant sa jeunesse: "Je le mettais, écrivait-il en 1859, au-dessus de tout pour l'ampleur et la douceur du flot poétique. Il me semblait en le lisant que je voyais mes émotions couler de mon cœur, et que c'étaient là les pensées qui s'efforçaient de chanter en moi." ${ }_{42}$

Le charme, toutefois, ne persista pas. Vint la malheureuse publication de Jocelyn; le goût de Veuillot, qui, à cette époque, se laissait de plus en plus éprendre à l'austère grandeur des classiques du dixseptième siècle, ${ }^{43}$ réagit vivement devant cette fade pastorale: "...le sujet lui en paraît choquant, le héros faux en tout, dans son caractère comme dans son langage" 44 "et plus ennuyeux que le vainqueur d'Ivry et de Gabrielle, célébré sur le trombone de Voltaire." 45

Le poète, en Lamartine, ayant "abdiqué", suivant l'expression de Barrès ${ }^{46}$, après la parution des Recueillements poétiques, c'est

39. Cf. Abbé Pierre Fernessole, Les Origines littéraires de Louis Veuillot (18131843) (Paris, 1922), 398.

40. Lettre de Montalembert à l'abbé Roëss, 12 février 1840. Cité par André Trannoy, Le Romantisme politique de Montalembert avant 1843 (Paris, 1942), 451.

41. Nous n'avons que le propre témoignage rétrospectif de Louis Veuillot, car il n'écrivit rien, alors qu'il était "petit journaliste" à Rouen et à Périgueux, sur Lamartine. Cf. Abbé Pierre Fernessole, Bio-Bibliographie de la jeunesse de Louis Veuillot (1813-1843) (Paris, 1923).

42. Cà et Là (Tome VIII des Oeuvres complètes, Paris, 1926): 530-531.

43. Cf. Eugène Veuillot, Louis Veuillot (Paris, [s.d. 1), I: 88.

44. Fernessole, Les Origines..., 132.

45. Cà et $L d: 531$. - L'hypothèse suivante de $M$. Guillemin n'est guère plausible: "Il est tout à fait probable qu'en 1836, Veuillot, d'ailleurs non catholique encore, ne fut pas, tant s'en faut, parmi les détracteurs de Jocelyn". (Le Jocelyn de Lamartine, $696)$.

46. Maurice Barrès, L'Abdication du poète (Paris, 1914). 
l'homme politique que Louis Veuillot eut à apprécier lorsqu'il devint rédacteur de l'Univers.

Une première occasion s'offrit, lorsque Lamartine prononça, le 4 juin 1843, à Mâcon, le fameux discours dans lequel il annonçait sa volte-face vers la gauche, à la stupeur d'un Sainte-Beuve que "ce torrent de magnifiques paroles en sens tout contraire au courant d'hier" 47 indigna profondément, mais à la grande satisfaction du parti républicain qui vit, en l'orateur mâconnais, "un allié avec l'espoir d'acquerir plus tard un illustre adhérent" 48.

Après avoir expliqué pourquoi il était passé à l'opposition, Lamartine s'écriait: "Le droit partout, la liberté pour tous, voilà pour nous la démocratie! voilà le peuple!" Il faut réaliser cette "pensée sainte et divine de la démocratie et de la Révolution française, puisque cette pensée, au fond, n'est qu'une émanation de l'idée chrétienne appelée à la politique"; l'orateur résumait ses aspirations dans un toast "a l'accomplissement régulier et pacifique des destinées de la démocratie" 4 .

Ce discours produisit un immense effet. Michelet écrivit à son ami pour lui dire que c'était son "évangile politique" et il ajoutait: "Vous aurez été notre prophète, notre précurseur. Vous serez celui que nous attendons". 50 Victor Considérant et Jules Bastide n'étaient pas moins enthousiastes. ${ }^{51}$

Mais si ces témoignages avaient leur prix, l'opinion de Louis Veuillot, au jugement de Louis Barthou, "dut surprendre et flatter plus agréablement Lamartine". 52

Ce n'est pas à dire que tout fut miel dans l'article du journaliste. Mais il ne ménagea pas les éloges. Il compara le talent de "l'illustre orateur" à celui d'O'Connell. Il trouva dans son discours "une rare magnificence", des "illuminations": “...l'on y reconnait parfois, avouait-il, la pensée d'un homme d'Etat, et plus souvent encore on y

47. Lettre de Sainte-Beuve à Juste Olivier, 15 juin 1843. Correspondance générale de Sainte-Beuve (Jean Bonnerot, éd., Paris, 1947), t. V, première partie: 167.

48. Georges Weill, Histoire du parti républicain (1814-187Q) (Paris, 1928), 174.

49. Cité par Louis Barthou, Lamartine orateur (Paris, 1916), 197.

50. J.-M. Carré, loc. cit., 195.

51. Cf. Barthou, op. cit., 197, 198.

52. Barthou, ibid., 198. 
sent l'âme d'un homme de bien. Jamais les orateurs de l'opposition, jamais ceux du Gouvernement n'ont eu d'inspirations pareilles."

Louis Veuillot arrivait ensuite à l'idée centrale du discours. Lamartine voulait "l'accomplissement régulier et pacifique des destinées de la démocratie". Le rédacteur de l'Univers ne formulait aucune objection contre ce programme. Bien plus, il l'acceptait volontiers: "Nous aimons, écrivait-il, tout développement régulier et pacifique, parce que tout ce qui se développe de la sorte est chrétien, et, s'il plaît à Dieu que la démocratie forme la base des institutions futures, nous n'aurons rien à objecter contre un fait qui a cessé d'être nouveau depuis dix-huit cents ans."

Mais cette démocratie était-elle celle de Lamartine? Là était le point délicat, la matière à controverse. Veuillot ne voulait pas se faire illusion. Il prônait une démocratie où l'Église eât sa part de liberté; or, malgré toute sa bonne volonté, le journaliste ne pouvait croire que ce fat celle de l'orateur: "Toute la largeur de ses vues, insistait-il, tout l'effort de son génie se bornent à rassembler des nuages et à former des tempêtes là où le Gouvernement s'exténue a maintenir le calme plat. Mais une boussole, mais un astre au ciel, mais un port dans l'avenir, il n'en connaît point."

Et "avec un instinct divinatoire dont il faut lui faire honneur", ${ }^{53}$ Louis Veuillot prévoyait, sept ans à l'avance, l'issue tragique de la carrière d'un grand homme d'État, qui échouerait lamentablement, pour avoir négligé, selon lui, d'assurer à l'Église la jouissance de ses légitimes libertés: "La démocratie qu'il nous peint si belle ne sera jamais, s'il la fait triompher, qu'une révolution où il aura pour un jour le premier rang, et qui, puissante, comme un orage, passera vite et laissera tout à refaire après qu'elle aura passé." Un tel destin lui est réservé, parce qu' il suit de trompeuses lueurs. Il travaille pour lui, pour un parti, il travaille pour un jour; il ne saurait être ni l'homme d'un peuple, ni le révélateur d'un avenir. Et pourquoi Dieu appellerait-il a tant d'honneur celui dont le cœur trop faible, trébuchant sous le poids du génie, s'est laissé, comme une femme, gagner à la louange et aux passions?" 54

53. Barthou, ibid., introduction, VIII.

54. Toutes ces citations sont extraites d'un article de Veuillot, daté du 10 juin 1843. Melanges (tome XXVII des Oeuvres complètes, Paris, 1933), I: 469-478. 
Ainsi, l'attitude de Veuillot à l'égard de Lamartine était nette, sans compromission. Si le journaliste admirait vivement l'orateur génial aux vues élevées exprimées dans une "langue magnifique, pittoresque, enchantée" ${ }^{55}$, il ne pouvait accorder sa confiance au politique qui écartait l'Église de son programme ${ }^{56}$. Les deux hommes s'étaient heurtés une première fois. Ils devajent se heurter, et plus rudement, trois ans plus tard, à propos de l'affaire Thions. Lamartine qui, jusque-là, avait gardé une attitude respectueuse envers l'Église catholique, va la traiter "en ennemie"; cet incident lui fournira l'occasion de combattre "contre elle". ${ }^{57}$



L'abbé Claude Thions, ${ }^{5} 8$ né le 25 janvier 1800 , était curé de Chânes, en Saône-et-Loire, depuis 1829. Il s'était mis en relation avec son illustre voisin, le châtelain de Saint-Point, depuis 1838. L'amitié de Lamartine, secondée par le prosélytisme de Dargaud, ne fut pas sans influence sur l'orthodoxie du pasteur, laquelle peu à peu gauchit.

55. Timon, Livre des Orateurs (Paris, 1847, dix-septième 6́dition), II: 249.

56. Quelques mois après le discours de Mâcon, Lamartine publiait dans son journal, le Bien public, les 26 et 30 novembre 1843, deux articles sur L'Etat, l'Eglise et l'Enseignement, que l'Univers, avec quelques réserves sur certains avancés, reproduisait in extenso. A Théophile Foisset, qui réclamait contre cette inser tion. Louis Veuillot écrivait qu'll avait "vu clair tout du premier coup dans son pathos" (Correspondance (t. XVI des Oeuvres complètes, Paris, 1931), II: 21), mais, expliquait-il à Montalembert, "M. de Lamartine nous a donné sans le vouloir un très bon coup de main. Toutes les erreurs de son esprit n'empêchent point que par son moyen la nécessité de la liberté d'enseignement et quelque chose de plus n'ait pénétré de vive force dans toute la presse." (Correspondance, II: 16) - Montalembert ne se faisait guère plus d'illusion que Veuillot sur l'appui que les catholiques pouvaient obtenir de la part de Lamartine dans leurs revendications de la liberté d'enseignement: lui aussi, il s'était rendu compte que le grand écrivain avait abandonné ses croyances antérieures; dans une lettre qu'il lui écrivait, le 27 novembre 1844, il lui en marquait sa peine en termes délicaț mais clairs: "Laissez-nous déplorer qu'une nature aussi élevée que la vôtre ne soit pas irrévocablement ancrée sur ce rocher de la certitude catholique où le chantre des Méditations et des Harmonies semblait avoir planté pour toujours son drapeau" (Cité par P. de Lallemand, op. cit., 89).

57. J. des Cognets, op. cit., 378.

58. Tous les détails sur l'équipée de Thions ont été donnés par M. des Cognets, ibid., 356-378, et surtout par M. Guillemin, "Lamartine et l'affaire de l'abbé Thions" dans son ouvrage, La Bataille de Dieu (Editions du Milieu du Monde, [1944), 49-120. Nous nous contentons d'indiquer les faits essentiels en utilisant les recherches de ces deux érudits et l'Univers de novembre 1846. - M. des Cognets écrit Thyons, tandis que l'Univers (Louis Veuillot connaissait la signature autographe de l'extravagant abbé) et $\mathbf{M}$. Guillemin, Thions. Nous avons adopté cette dernière orthographe. 
En 1844, le curé de Chânes donna un premier indice de son évolution, en refusant de signer le Mémoire que l'Épiscopat de France avait rédigé en vue d'obtenir la liberté de l'enseignement secondaire; ce coup de tête valut à Thions quelques mots d'éloge dans le journal de Lamartine, le Bien public, numéro du 11 aout 1844.

Trois semaines plus tard parut dans le même journal un grand article, dans lequel l'abbé Thions exaltait l'enseignement neutre de l'Université et s'en prenait aux Jésuites, ces "immobiles".

L'évêque d'Autun, Mgr d'Héricourt, usa de mansuétude pendant plus d'un an. Cependant, des dénonciations de plus en plus précises touchant la doctrine et la conduite du curé de Chânes parvinrent à l'évêché. Enfin, le 25 octobre 1846, l'abbé Thions fut mis en demeure de signer la profession de foi de Pie IV. Il s'y refusa. Lamartine, qu'il était allé voir le lendemain, à Monceau, lui donna raison; Dargaud exultait:... "le curé de Chânes, écrit-il dans ses Mémoires, a pris courageusement son parti; il a remis les clefs de son église. Il est rentré dans sa liberté de penseur et de citoyen. Il n'est plus catholique ni même chrétien à la manière des protestants. Il est philosophe." 59

Pour rendre publique auprès de ses paroissiens la protestation de Thions, Lamartine rédigea de sa propre main une déclaration que le curé lut en chaire. Le prêtre donnait les motifs de sa démission et prenait cavalièrement parti du document qu'on lui avait demandé de signer. Il ne voyait dans cet acte épiscopal "que deux choses: l'abus d'autorité qui vient sonder à toute heure le secret de la conscience et la contrainte morale exercée contre un prêtre à qui l'on donne à choisir entre la profanation de sa pensée et la perte de son pain". Il n'avait pas hésité: il avait "choisi de perdre [ son ] pain". "J'ai racheté, accentuait-il, la complète indépendance de ma conscience au prix de ma profession sur la terre, et tout en m'affligeant d'être séparé de vous, j'ai remercié le ciel de m'avoir fait reconquérir à ce prix la liberté des enfants de Dieu." Il avouait qu'il luj en coûtait de s'éloigner des habitants de Chânes, "mais vous auriez cessé de m'estimer, leur prêtaitil gratuitement, si j'avais acheté par une complaisance équivoque le bonheur de finir mes jours au milieu de vous, et j'aurais perdu ma propre estime si je m'étais engagé à enchaîner dans les liens d'une formule arbitraire une pensée qui n'est sainte qu'à la condition de

59. Cité par Guillemin, ibid., 78. 
rester libre et dont je n'aurais pas à me glorifier devant Dieu si je ne pouvais la discuter avec ma raison." 60

Le Siècle, le célèbre quotidien anticlérical de Paris, publiait cette déclaration le 3 novembre. Deux jours plus tard, l'Univers enregistrait l'esclandre par ces lignes sarcastiques:

M. l'abbé Thions, qui fit il y a deux ans des manifestations fort ridicules et assez inconvenantes dont le Siècle le loua beaucoup, paraît s'être, à la fin, attiré de fâcheuses affaires. Une lettre qu'il adresse à ses paroissiens et qu'il publie dans le Siècle, nous apprend qu'il a donné sa démission de curé de Chânes, pour ne pas signer et même pour ne pas lire une profession de foi qu'un grand vicaire était venu lui présenter au nom de son évêque. Nous manquons absolument de détails sur cette aventure, et nous ne sommes pas disposé à croire M. Thions sur parole. Les choses n'ont pas dû se passer aussi dramatiquement qu'il le dit; mais d'après ce que nous connaissons de lui, nous trouvons tout simple que ses supérieurs aient cru devoir s'assurer de sa foi et de son bon sens. Sa lettre aux paroissiens de Chânes ne prouve pas qu'il possède ces deux choses dans la mesure nécessaire. On y voit un homme qui se pose en victime de la tyrannie épiscopale, il dit qu'il a racheté la complète indépendance de sa conscience au prix de sa profession et de son pain sur la terre; il remercie le ciel de lui avoir fait reconquérir la liberté des enfants de Dieu, etc., etc. Toute cette emphase sonne assez mal. Un bon prêtre, et qui a du bon sens, ne s'indigne pas si fort d'être soupçonné, même injustement; il n'adresse pas, à ses paroissiens et au Siècle, les explications qu'il refuse à son évêque. Nous trouvons M. Thions fort heureux s'il continue à n'être que ridicule. ${ }^{6} 1$

Bafoué, l'abbé Thions se résolut à répondre. Il fit encore appel a Lamartine, qui s'était prêté si complaisamment à sa première demande. Il ne fut pas déçu dans son attente, et c'est le grand homme qui libella la lettre datée de Chânes, 13 novembre $1846,{ }^{62}$ et signée: C. Thions, qui fut insérée dans l'Univers du 17 novembre.

Après avoir exprimé sa surprise des "interprétations odieuses" qui s'étaient attachées à son acte, l'abbé Thions justifiait à sa manière 80-83.

60. Le texte intégral de Lamartine-Thions est reproduit par Guillemin, ibid.,

61. Univers, 5 novembre 1846.

62. Louis Veuillot reçut cette lettre le lendemsin. Univers, 17 novembre 1846. 
ce qu'il appelait "un acte de conscience et d'abnégation", qu'il osait, impudemment, comparer aux persécutions subies par les apôtres et les martyrs pour rester fidèles à leur foi! Comme eux, loin de récriminer, il acceptait l'adversité qui purifie et qui sauve: "Le coup qui me frappe, papelardait-il, est tombé durement, mais il tombe juste. Le joug me pesait. On me le brise sur la tête. Je ne murmure pas. Le coup qui me frappe me délivre. Que Dieu et la main dont il se sert soient bénis!"

Thions accepte donc l'exclusion prononcée contre lui. Il n'est plus catholique. Quelle sera sa nouvelle profession de foi ? Ce sera celle de son siècle, ou plutôt du dix-huitième. C'est la première fois que Lamartine se prononce aussi carrément. Il se croit assuré, sous la signature protectrice, de pouvoir dire nettement sa pensée, sans susciter des clameurs réprobatrices dans le camp catholique.

Ce siècle, écrit-il bravement, a... la folie de tendre avidement, par tous ses efforts, par toutes ses aspirations, par tous ses sacrifices, à réunir dans un magnifique acte de foi, Dieu et la raison, la tradition et le raisonnement, le passé et l'espérance. Il a la folie de vouloir que sa raison soit religieuse et que sa religion soit raisonnable. La raison sans la foi lui semble profane, la foi sans la raison lui semble ténébreuse. Il veut à tout prix les concilier pour sanctifier son intelligence par la raison, comme la religion a sanctifié ses actes par la vertu. Eh bien, Monsieur, je le confesse, je suis plus ou moins malade de la maladie de mon siècle; je suis plus ou moins atteint de sa religieuse folie. ${ }^{63}$

"Cette fois, enhardi par l'incognito, Lamartine a bien proclamé mot à mot le credo de Dargaud!" 64

Mais il ne comptait pas avec la maladresse de Thions et la perspicacité de Veuillot, qui avait vite éventé la mèche. ${ }^{65}$ Ce dernier donnait à ses lęcteurs les détails suivants sur la lettre qu'il venait de recevoir de Chânes. C'était "une copie soignée sur cinq feuillets numérotés

63. Texte intégral dans l'Univers, 17 novembre 1846; reproduit in extenso par J. des Cognets, op. cit., 369-373, et par Guillemin (d'après le manuscrit même de Lamartine), op. cit., 98-101.

64. J. des Cognets, ibid., 373.

65. Veuillot écrivait à Du Lac, alors novice à Solesmes: "Vous avez vu notre polémique contre ce pauvre hère de Tions [ sic]. Je crois que c'est Lamartine qui a la bêtise de lui faire ses lettres." (Correspondance, II: 223). 
prudemment, et ne portant d'écriture qu'au recto, pour donner au travail du typographe toutes les facilités désirables. Le papier, très beau et très aristocratique, [ était ] timbré d'une couronne de comte et du chiffre A.L."

Veuillot se fit fort de démontrer que "ces détails [avaient] leur prix". Ironiquement, il félicitait "M. Thions d'avoir pris un secrétaire": "Nous ne savons, remarquait-il caustiquement, si c'est son écriture et son orthographe que nous avons sous les yeux, mais à coup sûr ce n'est point là son style, pas plus que son papier. Ni l'un ni l'autre ne viennent de Chânes." Pour convaincre ses lecteurs, le journaliste citait des passages, en vers et en prose, des productions antérieures du curé démissionnaire; il n'avait aucune peine à prouver que le style de Thions, d'abord ampoulé et bizarre, s'etait soudain raffermi et délesté de ses métaphores empruntées à un biblisme de mauvais aloi. Puis il venait au cœur du litige et écartait d'une main dédaigneuse les sophisme de Thions-Lamartine :

Il s'agissait de savoir si Mgr l'Évêque d'Autun avait eu ou non des motifs suffisants pour remplacer $M$. Thions dans ses fonctions de curé de Chânes. Après la lettre de ce dernier, la question est videe: Habemus confitentem reum...; on n'exige pas sans doute que les évêques laissent le gouvernement des paroisses à des prêtres qui ont des accointances avec les protestants, et qui se révoltent à la pensée de signer la profession de Pie IV, sous prétexte que ce symbole vieilli ne concilie pas la raison et la foi. Pour nous, c'est sans difficulté que nous l'avouons, dussent $M$. Thions et $M$. son secrétaire trouver que nous n'entendons rien à la liberté religieuse: nous trouvons fort bon que de tels prêtres soient privés de leurs fonctions, même à l'entrée de l'hiver.

Après avoir déploré que le secrétaire de Thions se fût donné Je tort immense de "l'embarquer dans le galimatias impie qui termine sa lettre", Louis Veuillot n'était pas fâché d'adresser une leçon véhémente aux deux compères:

...vous n'étiez pas curé de Chânes uniquement pour habiter le presby tère et pour gagner votre pain, mais pour conduire fidèlement un peuple fidèle. Du jour où vous avez cessé d'être catholique, du jour où votre conscience s'est révoltée à l'idée d'obéir à votre évêque, et de signer le symbole que tout vrai catholique doit sceller, non seulement de son sang, mais de ses larmes et de ses humiliations, ce jour-là vous avez commencé d'habiter 
la maison d'autrui et de manger un pain qui n'était plus à vous. On ne vous a pas plus fait tort en vous ôtant les clefs de votre église qu'on ne fait tort à un homme de guerre en lui reprenant les clefs de la citadelle qu'il se propose de livrer à l'ennemi. Voilà ce que votre secrétaire auraît dû comprendre, si votre logique ne peut aller jusque-là. ${ }^{66}$

Lamartine se préoccupait fort peu de la leçon que Veuillot voulait lui do nner. Ce qui était plus grave à ses yeux, c'est que son jeu était décou vert. Jusque-là, dans cette polémique, il avait pu exprimer, en toute quiétude, ses idées les plus intimes sur la question religieuse. Thions avait été un prêtre - nom bien commode. Mais voici qui est de conséquence pour le député de Mâcon, car malgré son déisme, Lamartine ne voulait en aucune façon embarrasser son action politique par des attaques directes contre les catholiques: ce diable de Veuillot vient de pénétrer ses machinations, et le Siècle, sous couleur de houspiller l'Univers, admet la collaboration de l'écrivain à l'affaire, tout en déclarant lestement qu'il s'intéresse bien peu à la "part plus ou moins grande qu'aurait prise $M$. de Lamartine à la rédaction de la lettre de l'abbé Thions" ${ }^{67}$.

Cette fois, le nom de Lamartine a rebondi dans la polémique et dans le grand public. Veuillot s'en empare et raille:

Ah! c'est M. de Lamartine qui s'amuse à écrire sous le nom de M. Thions! Nous ne faisions que nous en douter; mais en renouvelant à $M$. Thions tous les compliments que nous lui avons faits sur le choix de son secrétaire, que veut-on que nous pensions du catholicisme de ce prêtre, qui refuse de signer la profession de foi de Pie IV, et qui signe une profession de foi formulée par l'auteur de la Chute d'un Ange? 38

Le $m$ asque est bel et bien arraché. Aussi Lamartine, qui constate le bruit déplorable qui se fait autour de son nom, grâce à la circulation des deux journaux les plus influents de Paris, estime qu'il importe de retirer au plus tôt sa carte d'un jeu devenu par trop dangereux. Aussi somme-t-il Thions d'adresser à Louis Veuillot une lettre qui dégagera sa responsabilité. Ce qui fut fait 69 .

66. Univers, 17 novembre 1846.

67. Cité par l'Univers, 19 novembre 1846.

68. Univers, 19 novembre 1846.

69. Cette lettre est reproduite par Guillemin, op. cit., 105-106. 
Quelques jours plus tard, le Bien public publiait un article, signe***, qui était de Lamartine, ainsi qu'il en informait Dargaud, le 27 novembre. Avec la désinvolture d'un grand seigneur, il repoussait l'absurde fable où la malignité de deux journalistes lui faisait jouer un rôle ridicule: "M. de Lamartine est resté... entièrement étranger à la résolution de $M$. Thions... Quant au papier sur lequel il aurait écrit ses lettres, nous ignorons complètement s'il l'a emprunté ici ou là. Ces détails de ménage nous intéressent peu. Jean-Jacques Rousseau écrivit, dit-on, le Vicaire savoyard sur du papier emprunté au curé de Montmorency. Ce brave curé ne répondait ni du génie ni des hérésies du pauvre vicaire." 70

Ce démenti catégorique une fois formulé, Lamartine n'était que plus à l'aise pour "élever le débat" et rassurer par une profession de foi hardie les libres penseurs qui pourraient blâmer sa tiédeur et sa trop prompte retraite. Il se défend d'abord de traiter la question "du point de vue ecclésiastique". C'est seulement "du point de vue politique" qu'il dénonce "la tyrannie dans laquelle se trouvent placés soixante mille prêtres en France". Enrôlés "avant l'âge du discernement" ils sont enchaînés à une croyance qu'ils ne peuvent plus rejeter sans se mettre au ban de la société. Et cependant "quel homme est sâr de penser à quarante ans ce qu'il pensait à vingt-cinq ans?" D'ailleurs, qui donc a le droit de définir la vérité, d'imposer un credo a l'esprit humain? Personne. Dieu seul le pourrait, "mais il ne l'a pas fait, car il fait la pensée active et l'homme libre depuis le premier jusqu'au dernier de ses jours." 71

L'esclandre d'un curé de campagne a donc procuré à Lamartine l'occasion d'aller jusqu'au bout de sa pensée. Et c'est le rédacteur de l'Univers qui l'a forcé dans les retranchements où il abritait prudemment son déisme. Il est bon de se rappeler ces faits pour apprécier sans parti pris l'attitude ultérieure des deux hommes.

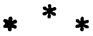

Du 17 mars au 11 juin 1847 parurent les huit volumes de l'Histoire des Girondins. Cette publication était attendue avec fièvre. Malgré

70. Cité par Guillemin, ibid., 109.

71. Nous citons une partie de l'analyse de l'article de Lamartine, par M. des Cognets, op. cit., 376 
les déboires dont Lamartine avait accablé les catholiques, ceux-ci conservaient encore un reste d'espoir de voir le grand écrivain revenir à la foi de son enfance. "Quand M. de Lamartine, écrivait l'abbé Charles-Marin André dans les Annales de philosophie chrétienne, fit savoir au public qu'il allait à son tour parler de la Révolution française et évoquer ces années mémorables, beaucoup de ceux qui l'ont aimé jadis conçurent naïvement quelques lueurs d'espérance. Cet enfant prodigue du génie s'enfoncerait-il définitivement dans les ténèbres ou reviendrait-il d'un pas vers la lumière ?" 72

Même Louis Veuillot, qui devait pourtant savoir à quoi s'en tenir, grâce à sa polémique récente avec Thions-Lamartine, laissa surprendre sa bonne foi. L'Univers du 14 mars 1847 insera, en feuilleton, un fragment du cinquième volume, intitulé: Le second mariage de Danton, précédé de quelques remarques laudatives. On y applaudissait "la merveilleuse facilite" de "l'historien sorti tout armé du cerveau du poète"; on invitait les lecteurs à "entrevoir", grâce à l'extrait soumis à leur appréciation, "combien [serait] nouvelle l'Histoire des Girondins; nouvelle par les détails inconnus jusqu'ici comme par la pensée qui choisit, pénètre et juge les événements ou les hommes." 73

Encore une fois, on avait fait trop confiance à Lamartine. Alors qu'un Michelet se montrait agacé de trouver dans l'ouvrage de la "tolérance" à l'égard de la religion, ${ }^{74}$ les catholiques y purent lire des éloges excessifs d'un Rousseau, d'un Robespierre et surtout d'un Voltaire. Aussi, autant on avait misé sur les dispositions de l'auteur, autant on se montra âpre dans l'invective. "...la clameur est générale", écrivait Veuillot en avril 1847. ${ }^{75}$ L'Univers, pour sa part, ne tardait pas à se repentir des louanges qu'il avait imprudemment insérées dans ses colonnes. Le 6 avril, le rédacteur écrivait que c'était pour lui "un devoir" de déclarer qu'il avait "presque regret" de ses "politesses". L'Histoire des Girondins était indigne de la "pensée", du "caractère" et "même des erreurs" de Lamartine, qui, dans son ouvrage, faisait "l'immorale apologie des caractères les plus souillés et des actes les

72. Anrales de philosophie chrétienne, 17 (janvier 1848): 68.

73. Univers, 14 mars 1847.

74. J.-M. Carré, loc. cit., 201.

75. Lettre de Veuillot à Du Lac. Correspondance, II: 271. 
plus odieux". Si l'historien était, aux yeux du journaliste, "froid jusqu'à la dureté, jusqu'à l'injustice, peut-être même jusqu'à la calomnie pour Louis XVI et Marie-Antoinette", en revanche, il était "complaisant et tendre jusqu'au ridicule pour les Mirabeau, pour les Fouchet, les Danton, pour d'autres encore, au-dessous de ceux-ci, qui ne durent qu'à l'immensité de leurs crimes d'être placés à part au milieu des plus noirs scélérats". Louis Veuillot reprochait encore à l'auteur d'avoir parlé de Robespierre "avec une sorte de vénération" et d'avoir fait de Voltaire comme "une espèce de précurseur du messie révolutionnaire" à qui rien ne manqua, "pas même la sainteté." 76

Ce n'était que quelques notes jetées à la hâte. Veuillot voulait faire un travail d'ensemble sur la question. Mais il fut devancé ${ }^{77}$ par Théophile Foisset, qui publia, dans le Correspondant, une étude sur l'Histoire des Girondins, d'autant plus sévère que l'on sentait sousjacente une douleur à peine contenue de voir l'écrivain bafouer l'Église et exalter ses ennemis les plus acharnés: "O poète! s'écriait-il, était-ce pour cela que Dieu vous avait envoyé?" 78

Foisset avait d'abord admiŕ Lamartine. ${ }^{79}$ Puis, étant presque son voisin, car magistrat à Beaune, il se trouvait à résider non loin de Mâcon, de Milly et de Saint-Point, et propriétaire de vignes comme lui, il n'avait pas tardé à se mettre en relation avec l'homme le plus célèbre de la région. C'est comme secrétaire du comité départemental

\section{Univers, 6 avril 1847.}

77. "Vous m'avez pris, écrivait-il à Foisset, le $30 \mathrm{mai}$ 1857, mes meilleures pensées, et d'une façon qui ne me permet plus que de copier." (Correspondance, II: 285) Une lettre de Lamartine au journal, l'Assemblée nationale, qui avait accusé l'auteur de ''Histoire des Girondins "d'avoir calomnié et flétri la reine Marie-Antoinette", permit à Veuillot de revenir sur "ces pages malheureuses" que Lamartine aurait dú couvrir "d'un silence éternel". Il écrivait, en 1853, que l'Histoire des Girondins n'était qu'une "mauvaise action"; l'historien, "un esprit qui ne fait pas le discernement du bien et du mal, un cœur que trouble et séduit le triomphe de l'iniquité"; ses idées étaient "détestables;" "sans doute il a des larmes pour les victimes. Eh! mon Dieu! des larmes, $M$. de Lamartine en a inondé la terre! Mais ce n'est pas en répandant des larmes qu'on se justifie d'admirer ceux qui répandent le sang." (Mélanges (T. XXXI des Oeuvres completes, Paris, 1934), V. 311-315).

78. Correspondant, 18 (25 mai 1847): 552.

79. Ayant fondé, avec quelques amis, la Société d'Etudes de Dijon, en 1821, Foisset demanda à Lamartine d'en faire partie. Le poète fut reçu membre de ce groupement littéraire en 1824. Cf. Cargill Sprietsma, Revue de Littérature comparée, 16 1936): 735, 742, note 2 . 
des vignerons qu'il adressa une première lettre, à la fin de 1829 ou au début de 1830, à son illustre compatriote. Le 18 mars 1832, après avoir lu la Politique rationnelle, le magistrat écrivait au futur député: “...j'ose dire que je vous appartiens." Au mois d'aout 1835, il était son hôte à Saint-Point.

Mais le fervent catholique décela vite l'évolution de l'écrivain vers le rationalisme. Pendant des années il garda le silence. Quand vint la publication de l'Histoire des Girondins, il se résolut à parler. ${ }^{80} \mathrm{Il}$ attaqua de front l'historien, l'artiste et le penseur.

Comme il se serait dispensé de cette tâche onéreuse, si le devoir n'avait pas commandé d'écrire! "Il y a vingt-huit ans, commençait-il par avouer, que j'admire, que j'aime M. de Lamartine. Mais la vérité a ses droits... il faut parler; il le faut. Les premiers volumes sont dans toutes les mains. Ils agitent depuis deux mois; ils troublent bien des jeunes intelligences."

L'historien, selon lui, était déplorable. La philosophie personnelle de l'auteur avait fâcheusement faussé le sens à donner aux événements qu'il racontait: 'Qu'est-ce qu'une histoire où la vérité historique est systématiquement sacrifiée à un fantastique idéal que nul ne rêva jamais dans les acteurs de ce drame sanglant? Qu'est-ce qu'un livre où l'aberration du sens philosophique et l'abus du sens poétique vont droit ainsi à l'obscurcissement du sens moral ?"'

Foisset reprochait surtout à Lamartine d'avoir haussé la stature des principaux acteurs de la Révolution, d'avoir magnifié le rôle d'un Mirabeau, d'un Robespierre, d'un Danton, d'un Marat. "Et quelle est la portée logique d'une telle apothéose, si ce n'est d'affaiblir, quoi que vous fassiez d'ailleurs, l'horreur du crime par cette auréole que vous faites rayonner sur le front du criminel? Quel en peut être l'effet direct, immédiat, inévitable, si ce n'est de ruiner l'autorité de la conscience publique, de faire au moins douter le lecteur de cette autorité, que dis-je? de la faire douter d'elle-même? Quel service à rendre au genre humain!"

Mais le comble était d'avoir fait, lui, "le poète des Méditations et des Harmonies", son "idole" de Voltaire: “...M. de Lamartine a

80. Ces détails sont empruntés à une étude de M. Cargill Sprietsma, intitulée "La martine et Théophile Foisset", publiée dans la Revue des Cours et Conferences, 37e année (15 déc. 1935): 49-63; (30 janv. 1936): 348-353; (29 fév. 1936) : 566-576; (30 mars 1936): 757-763; (30 avril 1936): 177-192. 
voulu, en plein $\mathrm{XIX}^{\mathbf{e}}$ siècle, renouveler et rajeunir l'apothéose de l'homme de Ferney. Cet homme qui n'aima jamais que lui, c'est un sage passionné pour la raison éternelle. Cet incroyant qui faisait ses pâques par devant notaire, c'est un martyr... Oui, M. de Lamartine a fait cette découverte, il a inventé Voltaire martyr."

L'artiste subissait d'aussi vives critiques. La composition était désordonnée, le sujet mal conçu et mal circonscrit; un même livre assemblait des événements qui ne se tenaient point: "Chaque division de l'ouvrage devrait avoir sa raison: ce doit être le fond des choses, et non la fantaisie de l'écrivain qui décide du nombre et de l'étendue des chapitres. Ici..., il n'en est point ainsi." Le style manquait de sobriété: "Jamais on n'a plus abusé de la métaphore, de l'antithèse, de l'hyperbole. Où en sommes-nous si les maitres écrivent ainsi ?"

Toutefois, c'est au penseur que Foisset s'en prenait avec le plus de vigueur: "...le magnifique langage de $M$. de Lamartine ondoie avec sa pensée; la parole est assurée, mais elle miroite comme le cou changeant de la colombe; l'affirmation n'est que sur les lèvres; au fond, il y a indécision, impuissance d'arrêter son jugement, scepticisme, irrésolution de l'esprit, indifférence du cœur." En d'autres termes, "M. de Lamartine manque d'un criterium en morale." Et le critique décelait l'origine de cette carence dans le fait que le célèbre écrivain avait "cessé d'être chrétien." 81

Les Annales de philosophie chrétienne ne furent pas en reste avec le Correspondant dans l'âpreté de la censure. L'abbé André résuma son réquisitoire dans ce jugement: "L'Histoire des Girondins est une méditation, moins que cela, une rêverie, anti-chrétienne, anti-historique, anti-nationale; un pamphlet en huit volumes contre l'Église, contre l'Histoire et contre la France." Et comme s'il eût craint que son verdict ne fat pas assez compréhensif, il ajoutait: "C'est comme Je rendezvous de toutes les aberrations de la pensée sur cette matière." 82

Luis aussi il reprochait avec véhémence à Lamartine son culte pour Voltaire. N'avait-on pas l'impression, après avoir lu son ouvrage, "que Voltaire aurait été la personnification du peuple de 1791, l'expression du peuple élevé jusqu'au génie; qu'il se serait dévoué à af-

81. Citations extraites des deux articles de Foisset, "Histoire des Girondins, par M. de Lamartine", Correspondant, 18 (25 mai 1847): 547-568; 19 (10 aout 1847): 414-444.

82. Annales..., 17 (janvier 1848): 69. 
franchir sa patrie et le genre humain d'un joug insupportable et odieux; qu'il aurait travaillé pour faire goûter à tous l'indépendance de la raison et le bonheur de la philosophie, et enfin, que, de ce foyer de l'intelligence, la vérité rayonnait à flots sur toutes les questions qui importent à l'homme ici-bas" ? 83

Pour détruire auprès des lecteurs de Lamartine - mais probablement sans grand succès ${ }^{84}$ - l'effet malheureux de ces éloges inconsidérés, le même publiciste entreprit, dans une série d'études vengeresses ${ }^{85}$, de lacérer la pourpre somptueuse que l'historien avait jetée sur les épaules de l'homme que, dix ans plus tard, dans son Roi Voltaire, Arsène Houssaye couronnerait prince de l'esprit.

Quant à la "théorie sociale de Robespierre jugée par M. de Lamartine", ce fut l'abbé Hébert-Duperron qui se chargea de la déchiqueter et de marquer au fer rouge "ce tyran qui organisa et régularisa la Terreur dans sa patrie, qui se joua avec le sang le plus pur de ses concitoyens." 86

La publication de l'Histoire des Girondins accentua done l'hostilité que les catholiques nourrissaient à l'endroit de Lamartine: la vogue inouie $^{87}$ que connut l'ouvrage ne fit que rendre plus intense l'amertume qu'ils éprouvaient de voir le grand écrivain, qu'ils avaient acclamé autrefois avec tant d'enthousiasme, s'écarter résolument de l'Église et de ses enseignements.

Ce "grand et déplorable succès," 88 ainsi que l'écrivait Veuillot, fut célébré magnifiquement par les Mâconnais, le 18 juillet 1847.

83. Ibid., 80.

84. Car les Annales avaient peu de circulation. Quelques années plus tard, Henry de Courcy écrivait à Jacques Viger (26 janvier 1856) au sujet de Augustin Bonnetty et de sa publication: "Ce brave philosophe s'imagine que la terre entière a les yeux fixés sur sa revue, tandis que personne ne la lit". (Archives du Séminaire de Québec)

85. Annales..., 17 (mars 1848): 205-219; 17 (juin 1848): 420-436; II, 4e série (juillet 1850): 7-26.

86. Ibid., IV, $4^{\circ}$ série (juillet 1851 ): 16.

87. "Le public haletant se jetait sur chaque volume, à mesure qu'il était mis en vente et le dévorait fiévreusement. ...Aucun roman-feuilleton n'avait davantage passionné la curiosité de la foule, ne s'était à ce point emparé de son imagination." (Paul Thureau-Dangin, Histoire de la Monarchie de Juillet (Paris, 1914), VII: 49)

88. Melanges (t. XXVIII des Oeuvres complètes, Paris, 1933), II: 562. Article du 23 juillet. 
Lamartine prononça, en cette occasion, un discours de deux heures, dans lequel il déploya, comme il l'écrivait à l'un de ses amis, Circourt, en août 1847, "juste autant du drapeau des idées modernes que le vent naissant le permettait." 89

En effet, il y faisait l'éloge, mais en termes mesurés, de la Révolution française. La manifestation dont il était l'objet, il la considérait comme la conclusion naturelle de son ouvrage: "...la France sent tout à coup le besoin d'étudier l'esprit de sa Révolution, de se retremper dans ses principes épurés, séparés des excès qui les altérèrent, du sang qui les souilla, et de puiser dans son passé les leçons de son présent et de son avenir." 90

A ces heureuses perspectives, il opposa, tout en ayant quelques paroles regrettables sur la liberté religieuse, dans lesquelles ne transparaissait que trop son déisme, les servitudes de la Monarchie de Juillet, dont il prédit la chute dans un mouvement oratoire, qui se terminait par un mot "vraiment meurtrier": “...après avoir eu les révolutions de la liberté et les contre-révolutions de la gloire, vous auriez la révolution de la conscience publique et la révolution du mépris." 91

Louis Veuillot, qui depuis 1842 combattait le régime flétri par le grand orateur ne pouvait, - malgré les défiances que de récentes expériences n'avaient que trop avivées - que louer l'homme qui se posait, comme lui, l'adversaire de la monarchie honnie: "Avec tous ses défauts, M. de Lamartine surpasse grandement tous les hommes d'opposition et de révolution qui s'ébattent stérilement à la tribune et dans la presse. ...Ce serait l'outrager de prononcer à cốté de son nom ceux des buffles mornes et pacifiés qui font semblant de traîner avec une morgue grotesque le char des idées de 89."

Le journaliste avait encore l'équité d'apprécier, dans ce "discours énorme, plein de nuages et d'éclairs", "une certaine intuition des besoins de ce temps-ci et de la situation que les événements nous ont faite"; le langage de l'orateur était "élevé et quelquefois magnifique". Toutefois, aux "aspirations d'une âme royale et d'une pensée vigoureuse" se mêlaient malheureusement les "préjugés", les "aveu-

89. Cité par Barthou, op. cit., 231.

90. Cité par Barthou, ibid., 227.

91. Cité par Barthou, ibid., 229-230. 
glements de l'esprit de secte" et les "lâchetés de l'esprit de parti". Et le catholique intransigeant ne pouvait pardonner à l'orateur d'avoir proposé "pour souverain remède à des maux nés de l'égoïsme et de la corruption politique et privée", "un déisme vague et le suffrage universel", de s'être prononcé contre "une religion définie [qui] lui paraîtrait un péril dans l'État": comment, raisonnait Veuillot, "se poserait-il en défenseur de la liberté d'une foi religieuse, lui qui n'en a aucune"?

Aussi le publiciste ne prévoyait-il pour Lamartine, comme en 1843, que l'échec final de son action politique: "Il croit composer un ciment et bâtir un édifice, mais il n'élève que des monceaux de poussière, et pour architecte, il appelle le vent." 92

Les succès prestigieux remportés par Lamartine pendant les premiers mois du Gouvernement provisoire durent faire douter Louis Veuillot de la justesse de son pronostic. Ce qui est sûr, c'est qu'il ne tarda pas à exhorter ses lecteurs à seconder l'action des nouveaux mấtres de la France: il avait trop souffert de voir la liberté religieuse brimée par la monarchie philippienne, pour qu'il marchandât son concours au nouveau gouvernement. Il voulait qu'on rendît justice aux hommes qui avaient mis sur leurs épaules le fardeau des affaires publiques. Il les louait d'avoir été "courageux et habiles"; à eux revenait "l'honneur de sauver de l'anarchie une société en révolution." 93

C'est un semblable éloge qu'il adressa au seul Lamartine, quand ce dernier eut réussi à écarter la menace du drapeau rouge: "Cette résolution, écrivait-il dans l'Univers, a sauvé la République, la France... Le drapeau rouge étant un signal de terreur, il a été rejeté, et la confiance et l'ordre se sont rétablis." 94

Toutefois, le Gouvernement provisoire ne tarda pas à susciter dans l'esprit du journaliste des craintes fondées. Une circulaire de LedruRollin, ministre de l'Intérieur, provoqua de sa part de vives critiques. ${ }^{95}$ Les mesures vexatoires du Commissaire du Gouvernement à

92. Citations extraites de l'article daté du 23 juillet 1847. Mélanges, II: 561-564 . 93. Article du 29 février 1848. Mélanges (t. XXIX des Oeuvres complètes, Paris, 1933), III: 171 .

94. Article du 9 mars 1848. Ibid., 177.

95. Cf. l'article du 9 mars 1848. Ibid., 176-179. 
Lyon, Emmanuel Arago, lui firent appréhender que le "caractère vraiment libéral, modéré, pacifique et conciliateur" de la Révolution de Février ne prît "un aspect menaçant et sinistre, persécuteur et irréligieux." 96

Mais Louis Veuillot ne pouvait ignorer les efforts méritoires de Lamartine pour contenir les menées jacobines de quelques-uns de ses collègues. D'ailleurs, l'éloquence enflammée du grand orateur, son attitude fière, son mâle courage durant les manifestations révolutionnaires du 17 mars et du 16 avril ne purent que provoquer l'admiration du journaliste. Le succès triomphal qu'il remporta aux élections du 23 avril et ses déclarations, lors des premières séances de l'Assemblée Nationale, l'enthousiasmèrent. Rendant compte du rapport présenté par Lamartine sur les relations extérieures, Louis Veuillot écrivait: "Le morceau est beau et noble. Il y a peu d'exemples dans l'histoire du monde d'une pareille communication faite au Sénat d'un grand peuple. On a souvent déclaré la guerre avec un immense et sublime courage; nous ne croyons pas qu'on ait jamais décrété la paix avec plus de majesté." 97

Les événements subséquents ne permirent pas au rédacteur de l'Univers de réitérer ces éloges. Le 9 mai, Lamartine, voulant conserver la confiance des républicains "avancés", informait l'Assemblée de son refus de faire partie de la Commission Exécutive, si Ledru-Rollin n'était pas désigné pour siéger en même temps que lui. Six jours plus tard, la journée du 15 mai portait une plus sérieuse atteinte à son prestige: Caussidière, le prefet de police, en qui il avait trouvé "le plus important et le plus habile" allié, ${ }^{98}$ s'étant compromis dans l'émeute, dut démissionner le lendemain, malgré les efforts oratoires de son illustre ami devant l'Assemblée pour le sauver. 9 " "Le résultat grave de

96. Article du 14 mars 1848. Ibid, 190.

97. Article du 8 mai 1848. Ibid., 234.

98. Pierre Quentin-Bauchart, Lamartine, homme politique. La politique intérieure (Paris, 1903), 249.

99. Le 17 mai, Lamartine adressait à Caussidière ces quelques lignes significatives: "Mon cher Caussidière, j'aurai un grand plaisir à vous revoir après cet orage qui vous emporte contre mon gré, et je ne doute pas que votre caractère et vos talents ne vous rappellent au service de la République. Elle vous doit beaucoup, selon moi. Je serai toujours votre témoin comme je l'ai été hier, et votre ami, si vous voulez." (Cité par Guillemin, Lamartine en 1848 (Coll. du Centenaire de la Révolution de 1848, Paris, 1948), 63n). 
cette séance, écrivait mélancoliquement Veuillot, c'est qu'elle a jeté quelque ombre sur l'attitude de M. de Lamartine." Non pas qu'il soupçonnât son caractère, mais "on se demande, de quel côté il est, avec qui il marche et qui peut compter sur lui". Et du coup, des défiances que la griserie des mois précédents avaient endormies, se réveillèrent pour ne plus s'assoupir: "Que $M$. de Lamartine y songe, ajoutait-il avec quelque solennité, il ne lui est pas permis de perdre la confiance publique; cependant il est en voie d'arriver là. Nous le disons avec douleur, nous qui avons tant de raison de ne pas nous abandonner aveuglément à lui." 100

Les Journées de Juin devaient anéantir sans espoir de retour les dernières espérances que certains conservaient encore fidèlement au grand homme dans le fond de leur cœur. Les amis de l'ordre, et a leur suite les catholiques, s'en remirent au général Cavaignac, dont la main de fer avait étranglé l'insurrection.

Désormais, c'est à grandes enjambées que Lamartine descendit les gradins de la défaveur et de l'humiliation. Autant on l'avait exalté aux premiers jours de la Révolution, autant on se montra dur pour lui lorsqu'il rencontra l'infortune. Quand il fut à peu près certain qu'il échouerait contre Louis-Napoléon Bonaparte, et que, rentrant a Monceau, un cortège se fut formé pour l'acclamer, lui procurant "la dernière flambée de la gloire" 101 Louis Veuillot lui décocha ces lignes: "Il est peu probable que M. de Lamartine soit cette fois élu président de la République, mais en attendant il est roi à Mâcon. Chaque jour ovation nouvelle et discours nouveau. Cette royauté est plus douce et moins périlleuse que l'autre; puisse-t-elle durer longtemps! M. de Lamartine y gagnerait de toutes manières, et la France aussi." 102

Deux jours plus tôt, ce n'était pas sous la forme d'un souhait qu'il s'était prononcé contre cette candidature. Contrairement à Lacordaire, Maret et Ozanam, qui dans l'Ere nouvelle l'avaient mise en avant, Louis Veuillot déclarait carrément: "Nous ignorons absolument quels mérites particuliers peuvent le [ Lamartine] recommander aux catholiques", et il motivait aussitôt son opposition par ces quelques mots:

100. Article du 16 mai 1848. Mélanges, III: 250.

101. Claudius Grillet, Un grand vigneron, Lamartine (Paris, 1933), 81.

102. Univers, 31 octobre 1848. 
"M de Lamartine a donné trop de gages à tous les drapeaux pour être adopté par aucun." 103

Il avait vu le chef du Gouvernement provisoire faire des avances à un Caussidière, à un Ledru-Rollin, à un Louis Blanc. Il attribuait à cette politique de concessions perpétuelles envers les révolutionnaires et les socialistes la faillite du régime qu'il avait accueilli chaleureusement. Désormais, c'est vers Louis-Napoléon qu'il tournait les yeux. Le prince, élu président de la République, le 10 décembre 1848, par les gages qu'il sut donner à l'Église, ne tarda pas à gagner la confiance du journaliste, et le 5 décembre 1851, c'est par un article décisif 104 que le rédacteur de l'Univers entraînait la grande masse des catholiques à accepter le coup d'État.

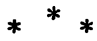

Le 2 décembre, qui marquait l'avènement du pouvoir dictatorial, précurseur de l'Empire, mit fin à la carrière politique de Lamartine. Un seul souci ne cessera désormais de le hanter: payer ses dettes.

Il était sorti ruiné de la Révolution de Février. "...les cinq ou six millions qu'il gagna - au moins - avec ses œuvres littéraires" 105 ne l'empêchèrent pas de se trouver à maintes reprises au bord de la faillite. En 1835, en 1839 et en 1843, il avait éprouvé de graves embarras d'argent. Le $1^{\text {er }}$ janvier 1848 , il constatait qu'il lui restait encore des dettes considérables, mais son avoir "tant en terres, maisons et mobiliers qu'en placements et propriétés littéraires" dépassait deux millions. ${ }^{106}$ La Révolution détruisit à jamais la précarité de cet équilibre. Durant les mois où il fut le chef du Gouvernement provisoire, Lamartine dut débourser largement pour faire face aux frais encourus par sa situation exceptionnelle. Aussi le 26 février 1849 écrivait-il à son notaire de Mâcon: "Je n'ai plus d'argent après mes énormes dépenses de 1848." 107

103. Article du 29 octobre 1848. Melanges, III: 337.

104. Melanges (t. XXXI des Oeuvres complètes, Paris, 1934), V: 1. - Cet article est cité in extenso par Jean Maurain, La Politique ecclésiastique du Second Empire, de 1852 à 1869 (Paris, 1930), 5.

105. J. des Cognets, op. cit., 439.

106. Guillemin, Lamartine: l'homme et l'auvre, 139.

107. Cité par Guillemin, ibid., 140. 
Pour se tirer du gouffre, il va se livrer avec frénésie au commerce des vins ${ }^{108}$ mais surtout à un labeur littéraire écrasant. Il sera le forçat de la plume. On a tout dit sur les affres qui furent son lot, de 1849 à sa mort, sur "le plus douloureux calvaire de détresse où jamais le génie ait conduit une de ses victimes de choix." 109 Tous ses biographes, ou à peu près, ont énuméré les œuvres qui furent le fruit de ce travail forcené. Trois seulement, parce qu'elles ont un rapport étroit avec le sujet de notre étude, vont retenir notre attention: Les Confidences, Raphaël, et surtout le Cours familier de littérature.

C'est en 1849 que Lamartine faisait paraître les deux premières. Louis Veuillot ne tarda pas à s'en occuper dans son journal. L'homme politique l'avait déçu; il fut impitoyable envers l'homme de lettres. Ce fut, aux termes de son biographe, "un éreintement de première classe." 110

Dès cette époque, le rédacteur de l'Univers signala deux points principaux sur lesquels sa critique devait revenir inlassablement dans la suite: l'exploitation "industrielle" de la littérature et l'équivoque soigneusement entretenue par l'écrivain au sujet de ses idées religieuses et de ses convictions morales.

Le journaliste déplorait, tout d'abord, que l'"illustre auteur" ne mit "aucune fierte" à livrer au public les secrets de son cœur, à faire "une exploitation de librairie" "du cimetière où dormaient les affections de sa jeunesse", car ce n'étaient que "des soucis d'argent" et le désir de "racheter la maison paternelle, que les huissiers assiégeaient", qui l'avaient poussé à écrire: "Le papier timbré a provoqué les Confidences." D'autres n'auraient pas aussi facilement consenti à "garder la fortune préférablement à l'honneur". Et Veuillot, puisqu'il s'occupait des souvenirs du poète, prenait un malin plaisir à citer parmi ces gens fiers, "qui ne trafiquaient point, qui ne concevaient même pas ces extrémités auxquelles on se résigne aujourd'hui", les propres parents de Lamartine: "Ils auraient laissé faire les huissiers."

Mais c'est sur l'absence de convictions morales révélées dans les deux dernières productions de l'écrivain, que le rédacteur de l'Univers

108. Cf. Claudius Grillet, Un grand vigneron, Lamartine.

109. Camille Latreille, "Lamartine. Les années de détresse et d'héroïsme." Correspondant, 274 (10 février 1919), 429.

110. Eugène Veuillot, Louis Veuillot (Paris, i s.d. ], dixième édition), II: 311. 
appuyait davantage: "En le lisant avec un peu de soin, écrivait-il, on se convainc que le bien et le mal, la vérité et l'erreur, et les mots euxmêmes ne sont pas pour lui ce qu'ils sont pour tout le monde. Il n'en fait pas la distinction; s'il les distingue, il les place à rebours."

Lorsqu'il parle de l'amour, "jamais un terme grossier, jamais un mot choquant n'échappe à $M$. de Lamartine... Il habille l'amour sensuel d'une longue robe blanche... Nul cynique, toutefois, ne s'est emporté à plus d'excès contre la religion, contre la morale, contre la pudeur. Seulement, ce que d'autres ont dit l'écume à la bouche, M. de Lamartine le dit avec politesse, le module avec poésie, le soupire avec sentiment." Le journaliste préférait, quant à lui, ce qui se dénonçait "franchement obscène et franchement impie." 111

Louis Veuillot s'était donc exprimé sans ambages sur le compte de Lamartine. Il reprendrait les mêmes critiques, mais plus âpres, lorsque l'écrivain eut essayé d'intéresser les États-Unis et le Canada à la vente de son Cours familier de littérature. Le conflit qui, depuis tant d'années, opposait l'auteur de Jocelyn aux catholiques, prit dans cette aventure une grandeur tragique. Alors que le grand homme malheureux confessait pathétiquement à son agent, Jean-Baptiste Desplace ${ }^{112}$ qui, depuis mars 1856, résidait à New-York: "Sans un secours d'Amérique du Nord je suis perdu," 113 le rédacteur de l'Univers s'indignait, ainsi qu'il l'écrivait rétrospectivement, de voir les "rabatteurs [ de Lamartine ] dans le Nouveau Monde" exploiter "son christianisme d'autrefois pour écouler les produits de son panthéisme d'aujourd'hui." 114 Il nous reste à raconter en détail cette équipée et à en indiquer les répercussions immédiates et éloignées.

(A suivre)

Frère Robert Srlvain, E.C.

111. Citations extraites des articles publiés au cours du mois de mars 1849. Mélanges, III: 425-454.

112. M. Séraphin Marion, loc. cit., écrit invariablement Desplaces. Or, les érudits qui, comme Jean des Cognets, le Marquis de Luppé, Gustave Charlier et Henri Guillemin, ont vu la signature autographe de Desplace, écrivent toujours ce nom sans $s$ final.

113. Cité par Gustave Charlier, Aspects de Lamartine (Paris, [ 1937 ]), 159. Lettre datée de Paris, 23 juin 1856.

114. Univers, 2 janvier 1858. Mélanges ( $\mathrm{t}$. XXXIII des Oeuvres complètes, Paris, 1935), VII: 300-301. 